for procrastination can be laid at our feet."I am, etc., Oxford.

Malcolm Donaldson.

\section{Lysergic Acid Diethylamide}

SIR,-As one who has been closely connected with the use of L.S.D. 25, both in research and psychotherapy since 1957, I would like to have this opportunity of clearing up some of the points raised in your recent correspondence. It must be agreed that the Sandoz decision to discontinue distribution of the drug was somewhat precipitous, and probably annoying to most people working with it. We must, however, as a profession take part of the blame for this. Together with some of your correspondents, I have attended numerous international conferences on the use of L.S.D. 25 and have lectured on this subject both in Europe and the United States. A number of us were asked by Sandoz, Basel, as long as four years ago, to form some sort of international medical body which would be responsible for setting up standards of practice and for recommending to the pharmaceutical firm names of investigators who were considered competent to work with this drug. Eventually, in May of last year, a number of us who attended a conference in Long Island laid down some foundations for such an organization. In the last few weeks some hurried attempts have been made to bring such an organization into being and I have been asked to chair one of its committees. To some of us it would seem like bolting the stable door after the horse has escaped.

For the past few months I have been in close contact with both Sandoz and the National Institute of Mental Health, and it seems that in this country L.S.D. 25 will continue to be available to bona fide investigators. It seems likely that in England similar arrangements may be made either with the Ministry of Health or with the Medical Research Council. Some official control of the distribution of L.S.D. 25 and other hallucinogens is essential. These drugs are unlike any others in use in psychiatry. The profound psychological effects produced by them put them in a category by themselves and they certainly cannot be compared with amphetamines. I believe that potentially L.S.D. 25 is of great value, not just as an aid to psychotherapy, but as a tool for the understanding of the functioning of the human mind.

Before leaving London to take up my present appointment, at the end of last year, I sent out a questionary on the use of L.S.D. 25 to a number of psychiatrists in the United States, Great Britain, and Germany. Detailed results of this will be published later this year. Briefly, a large percentage of psychiatrists in all three countries answered my questionary. In the British sample a considerable number of psychiatrists did not reply, while the most complete response came from Germany. A fair number of psychiatrists were against any use of L.S.D. 25 either in research or in therapy. It is interesting to note that when I wrote to these psychiatrists again in the last three months they all, almost unanimously, agreed that this drug should be studied further, and that it should not be lost to psychiatry altogether. It may be an encouraging sign that psychiatrists seem to respond in the same way as the rest of the population to the threat of control from outside and that they become interested in things as soon as these are forbidden.

The apparently widespread use of hallucinogen drugs is in itself an interesting sociological phenomenon which I am at present attempting to study. It seems that the L.S.D. takers are not of the same population group who are addicted to alcohol nor the same as those addicted to the amphetamines. The danger of course is that, while given to the so-called normal a single dose of L.S.D. produces no prolonged psychological changes, the same dose given to an unsuitable subject might have disastrous results. It is to be hoped that as its news value diminishes the extent of illicit L.S.D.-taking will also get less. It seems now that satisfactory arrangements are being made for bona fide investigators to have access to this drug.-I am, etc.,

University of Virginia Hospital, John BuckMan. Virginia, U.S.A.

\section{Buzzer Ulcers}

SIR,-Drs. P. Borrie and J. C. B. Fenton (16 July, p. 151) will be glad to know that their experience is not unique. I have two identical cases in my own practice.

The more severe was in a girl of 9 yearsa persistent enuretic and a very deep sleeper. The ulcers were deep and painless, and severe enough to need discussion with plastic surgeons. They healed slowly, but some final plastic operations are to be considered about two years after the incident (Fig. 1). The bell apparatus used is similar to the reported case, but the "pad" is different. There are two sheets of bonded metal foil (the upper perforated), and these are separated by a thin bed-sheet (Fig. 2). The mother noted that there was a deposit of " some silvery stuff " on the skin around the lesions, although the skin had been separated from the top foil by the normal bed-sheet.

My department has used this treatment for the past eight years and we have fifty machines in use. Calculated in terms of child-nights of exposure to risk two cases do

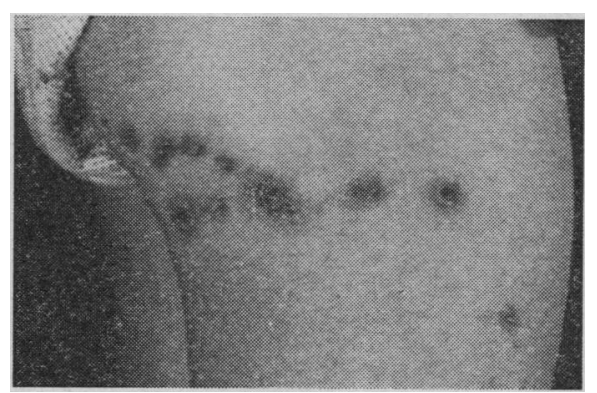

FIG. 1 not give cause for great alarm. I would be very glad, however, for modifications in design which would remove this complication, and enable us to continue to use our machines with confidence.-I am, etc.,

$$
\begin{aligned}
& \text { Royal Albert Edward } \\
& \text { Infirmary, } \\
& \text { Wigan, Lancs. }
\end{aligned}
$$

\section{Extrauterine Pregnancy and Intrauterine} Devices

SIR,-Ectopic gestation, as reported by Mr. R. Ramkissoon-Chen and Dr. Kong Ta-Ko (21 May, p. 1297), is not infrequently encountered with an intrauterine device (I.U.D.) in situ. According to the most recent tabulations of our Cooperative Statistical Programme, covering 22,400 women wearing I.U.D.s with an aggregate of more than 300,000 months of use, 588 pregnancies with device in situ were reported. Of these, 26 , or one in 23 , were ectopic. The incidence of ectopic gestation has important implications for the mechanism of action of the I.U.D.s. Statistical studies have shown that a group of 100 young couples discontinuing birth control after a period of protection may be expected to achieve 20 to 30 conceptions during the first cycle of exposure. In subsequent months the pregnancy rates decline, because the more highly fertile couples tend to achieve pregnancy early and are thus removed from the group at risk, which contains a steadily increasing proportion of less fertile couples. ${ }^{12}$

In the presence of an I.U.D. this process of selection is suspended, and it may be assumed that the maximum rate of fertilization is maintained. If the I.U.D. interfered with implantation on the uterine level but did not disturb events in the Fallopian tubes, fertilization of ova would continue at a monthly rate of 20 to 30 per 100 women. With 13 ovulations per year the annual rate of fertilization would be between 260 and 390 per 100 women. A certain fraction of these ova would implant ectopically. While the incidence of tubal pregnancy varies considerably between populations, a ratio of 0.3 per 100 fertilized ova is probably a conservative estimate, implying between 0.8 and 1.2 ectopic pregnancies per 100 women per year.

With approximately 25,000 woman-years of use of I.U.D.s reported, between 200 and 300 ectopic pregnancies would be expected, but only 26 did in fact occur. While the incidence of ectopic pregnancy is very high in relation to the number of pregnancies, it is very low in relation to the number expected on the assumption that the mechanism of action of the I.U.D.s operates on the uterine level. Thus, our statistical findings

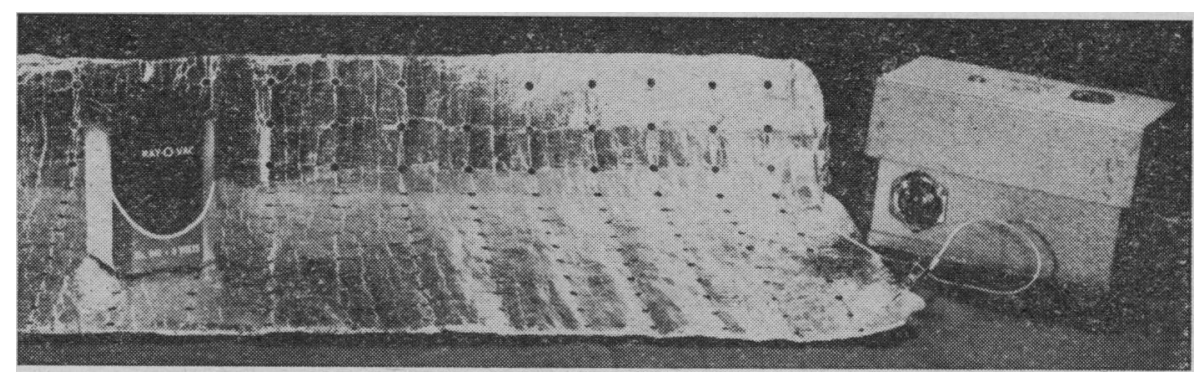

